\title{
Implementing the Mental Health Act 2001 in Ireland: views of Irish general practitioners
}

\author{
F. Jabbar, M. Aziz and B. D. Kelly* \\ Department of Adult Psychiatry, University College Dublin, Mater Misericordiae University Hospital, Dublin 7, Ireland
}

Objectives. The Mental Health Act 2001 introduced important reforms of Irish mental health law and services. This paper aims to provide an evidence-based exploration of general practitioners' views on the implementation of the Mental Health Act 2001.

Methods. We posted questionnaires to 1200 general practitioners in Ireland seeking their views on their experiences with the Mental Health Act 2001.

Results. Eight hundred and twenty general practitioners (68.3\%) responded. Among those who provided comments, a majority $(75.2 \%)$ provided negative comments. The most commonly occurring themes related to difficulties with transport of patients to inpatient facilities, form filling, time requirements and administrative matters. Other negative comments related to general practitioner recommendations for involuntary admission, training, mental health tribunals, applications for involuntary admission and the position of children. Minorities provided neutral (18.0\%) or positive comments $(6.8 \%)$, chiefly related to user-friendliness, transparency and improved communication.

Conclusions. General practitioners highlight a need for greater training and clear guidelines in relation to the Mental Health Act 2001. Their forthright responses demonstrate deep engagement with the new legislation and eagerness to see the Mental Health Act 2001 realise its full potential to improve the involuntary admission process and protect human rights, in the best interests of patients.

Received 18 May 2013; Revised 28 August 2013; Accepted 28 August 2013; First published online 13 November 2013

Key words: Family practice, formal, Ireland, legislation, mental disorders, social control.

\section{Introduction}

The Mental Health Act 2001 introduced important reforms of Irish mental health law, including revised involuntary admission procedures and automatic reviews of involuntary admission orders by mental health tribunals (Kelly, 2007; Kelly, 2009a; Kelly, 2009b; NíMhaoláin \& Kelly, 2009; Kelly, 2010). There is strong evidence that the new legislation both protects human rights (O'Donoghue \& Moran, 2009; Ramsay et al. 2013) and presents significant challenges to psychiatrists, stemming from increased workloads, more conflicted relationships with service-users and adversarial mental health tribunals (Jabbar et al. 2010).

The majority of individuals with mental illness are, however, treated in primary care (Casey, 2005). In addition, general practitioners (GPs) are involved in several specific procedures under the legislation, including examining patients, making recommendations for involuntary admission and (in certain cases) participating in organising transport to psychiatric inpatient facilities. As a result, changes in mental health legislation

\footnotetext{
* Address for correspondence: B. D. Kelly, Department of Adult Psychiatry, University College Dublin, Mater Misericordiae University Hospital, 62/63 Eccles Street, Dublin 7, Ireland.

(Email: brendankelly35@gmail.com)
}

are likely to present significant challenges to GPs, some of whom report that it can take 7 or more hours to complete an admission under the new legislation (Kelly et al. 2011).

Against this background, we performed a postal survey of GPs' views on the implementation of the Mental Health Act 2001 in Ireland. We have previously reported quantitative findings from this survey, indicating that $62.9 \%$ of GPs feel that the new legislation is not user-friendly (Jabbar et al. 2011). Majority of GPs who feel the legislation has affected their practice report increased workloads (85.3\%) and various other difficulties $(52.7 \%)$. GPs who received training about the new legislation are more likely to find it user-friendly $(43.0 \%$ v. $30.9 \%)$, and informal training (e.g. from colleagues) is just as likely as formal training to be associated with finding it user-friendly. The present paper aims to add greater depth and explanatory meaning to these quantitative findings by exploring GPs free-text comments about the legislation, drawn from the same survey.

\section{Methods}

We aimed to provide an evidence-based description of GPs' views on the implementation of the Mental 
Health Act 2001 in Ireland. To this end, we posted a questionnaire relating to the Mental Health Act 2001 to the practice addresses of every second GP listed in the Irish Medical Directory (Guéret, 2008); that is, we posted the questionnaire to 1200 of the 2400 GPs listed. Eight hundred and twenty GPs (68.3\%) responded to our survey.

The questionnaire enquired into basic details about the respondent's practice (urban/rural, number of GPs in the practice), training in the mental health legislation (none, formal or informal), changes in workload as a result of the legislation, changes in time spent with patients, changes in relationships with patients, and user-friendliness of the legislation and any reported problems with it. We stored, described and analysed data using the Statistical Package for the Social Sciences (SPSS Inc., 2003).

In addition to recording this quantitative information, our survey also included a free-text box seeking GPs' comments on their own experiences of the Mental Health Act 2001 since implementation. These free-text comments form the focus of the present paper, with the aim of adding greater depth and explanatory meaning to the quantitative results from our study (Jabbar et al. 2011). All positive, neutral and negative free-text comments were reviewed by two of the authors (F.J. and B.D.K.), who classified them into thematic categories, using an iterative procedure until no further categories or themes emerged.

\section{Results}

\section{Description of participants}

Eight hundred and twenty GPs (68.3\%) responded to our survey. Just over half of respondents worked in urban settings $(53.3 \%)$, one-third in rural settings $(34.2 \%)$ and the remainder in mixed settings $(12.6 \%)$ (Jabbar et al. 2011). Just under half (49\%) had received training in the new legislation; $62.9 \%$ felt the new legislation was not user-friendly; and, among GPs who felt the legislation had affected their practice, 85.3\% reported increased workloads.

\section{Free-text comments}

Four hundred and eleven GPs (50.1\%) provided comments about the Mental Health Act 2001 in the free-text area of the questionnaire (Table 1). Of those, $28(6.8 \%)$ provided positive comments, relating chiefly to issues such as the user-friendliness of the new legislation, transparency, the presence of guidelines, and improved communication and transfer arrangements. One GP commented that the new legislation is 'easier to manage than old Act' and another found it 'much more transparent'. Other GPs described it as 'more user-friendly' and 'less time-consuming'. Other comments included that it was now 'much easier to transfer patients to hospital'; the legislation 'works well'; and the 'benefits outweigh difficulties'.

Among those who provided comments, 309 GPs $(75.2 \%)$ provided a total of 329 negative comments. The most commonly occurring theme was transport of patients to inpatient facilities, which was mentioned in 112 comments $(34.0 \%$ of all negative comments). GPs cited 'ongoing difficulty in organising transportation' with specific concerns that the process is 'very timeconsuming' and a 'logistical nightmare'. One GP commented that it is 'difficult leaving a family to wait for escort' and another noted that 'the GP-patient relationship can be irretrievably damaged'. There were

Table 1. Comments from GPs about the implementation of Ireland's Mental Health Act 2001

\begin{tabular}{lrr}
\hline Type of comments & $n$ & $\%^{\mathrm{a}}$ \\
\hline Positive comment & 28 & 6.8 \\
Neutral comment & 74 & 18.0 \\
Negative comment & 309 & 75.2 \\
Categories of negative comments ${ }^{\mathrm{b}}$ & & 112 \\
$\quad$ Difficulties with transport of patients to approved centre & 79 & 34.0 \\
Issues related to form filling, time requirement and bureaucracy & 23 & 24.0 \\
Problems related to GP recommendation for involuntary admission & 18 & 7.0 \\
Deficits in training & 17 & 5.5 \\
Issues related to mental health tribunals & 11 & 5.2 \\
Problems with applications for involuntary admission & 4 & 3.3 \\
Issues related to involuntary admission of children & 65 & 1.2 \\
General, non-specific problems & 19.6 \\
\hline
\end{tabular}

GP, general practitioner.

${ }^{a}$ Overall, 411 GPs provided comments.

${ }^{\mathrm{b}}$ Three hundred and nine GPs provided a total of 329 negative comments. 
difficulties reported with transport from 'an offshore island' and one GP concluded that it is now 'impossible to get a seriously unwell patient... to the hospital'.

The second most common negative theme was form filling, time requirements and perceived bureaucracy, which formed the focus of 79 negative comments $(24.0 \%)$. GPs expressed views that the forms are 'not user-friendly', 'a minefield', 'very time-consuming', 'unbelievably cumbersome', 'difficult and very scary'. One GP commented that there are simply 'too many forms' and another concluded that 'an involuntary admission is now an absolute nightmare'.

The remainder of the negative comments $(n=138$; $41.9 \%)$ related other matters including GP recommendations for involuntary admission $(n=23 ; 7.0 \%)$, deficits in training $(n=18 ; 5.5 \%)$, mental health tribunals $(n=17 ; 5.2 \%)$, applications for involuntary admission $(n=11 ; 3.3 \%)$ and the position of children $(n=4 ; 1.2 \%)$. Certain GPs felt that the legislation was 'open to manipulation', 'not designed with patients' mental health foremost' and placed a 'very unfair burden' on GPs. Others complained that 'no formal training [was] received' and suggested that 'structured training... would be useful'. Regarding tribunals, one GP stated that a 'patient was released early on some technicality related to filling the forms' and another 'would prefer a system where relatives were not involved in signing forms' (i.e. making applications for detention). Regarding children, one GP reported that there was a 'major problem with 14-18 year olds' while another suggested 'a clear, unfussy algorithm for GPs to use'.

Looking at the legislation overall, individual GPs described it as 'unworkable', 'unwieldy', 'unusable', a 'nightmare', a 'complete disaster' and 'should be scrapped'. One GP felt the legislation had been 'designed by lawyers for lawyers' and another felt it was 'designed by individuals who have little or no knowledge of primary care'.

\section{Discussion}

\section{Main findings}

This study provides evidence of some positive reactions to the Mental Health Act 2001 among GPs, but greater evidence of negative reactions, especially in relation to difficulties with transport of patients to psychiatric inpatient facilities and myriad issues related to form filling, time requirements and administrative matters.

Strengths of this study include its relatively high response rate $(68.3 \%)$, its focus on an issue of considerable importance in primary care (Mental Health Act 2001) and the diversity of forthright responses received. Limitations include the relative paucity of information about respondents (e.g. length of time in practice) and the fact that we did not send reminders to GPs who did not respond, possibly introducing response bias; that is, it is possible that GPs with negative views were more likely to respond than those with positive views. Notwithstanding this concern, our study produced a significant diversity of positive, neutral and negative responses, highlighting many issues of clear concern to GPs about the legislation.

The negative comments that dominated many responses are of particular concern owing to the key roles GPs play in revised involuntary admission procedures. Following an application for involuntary admission, the patient must be examined by a registered medical practitioner (e.g. GP) within 24 hours of receipt of the application. If the GP makes a 'recommendation' for involuntary admission, a copy 'shall be sent by the registered medical practitioner concerned to the clinical director of the approved centre concerned and a copy of the recommendation shall be given to the applicant concerned' (Mental Health Act 2001, section 10(4)). It is a cause of considerable concern that some GPs find this procedure unwieldy, especially as much of this concern appears to relate to administrative matters such as form filling.

This additional workload, however, needs to be viewed in the context of the key motivation behind the Mental Health Act 2001, which was to bring Irish mental health law into greater accordance with international human rights standards, including the United Nation's Principles for the Protection of Persons with Mental Illness and the Improvement of Mental Health Care (United Nations, 1991). The Mental Health Act 2001 duly resulted in the removal of indefinite detention orders (that existed under the Mental Treatment Act 1945); introduction of new involuntary admission procedures; automatic, independent review of detention orders by tribunals; free legal representation and independent psychiatric opinions for patients before tribunals; and establishment of the Mental Health Commission to oversee implementation of the Act and standards of care. Many of these changes promote human rights, dignity and patients' autonomous exercise of capabilities (O'Donoghue \& Moran, 2009; Ramsay et al. 2013). While some increase in workload is probably inevitable in order to realise these benefits fully, future revisions of procedures related to the legislation could usefully seek to minimise additional administrative workloads for all involved.

\section{Transport of patients}

One of the key concerns among GPs highlighted in this study relates to transport of patients to inpatient facilities. 
This is a process in which the GP may play a critical role if the applicant cannot transfer the patient themselves. Under this circumstance, 'the clinical director of the approved centre... or a consultant psychiatrist acting on his or her behalf shall, at the request of the registered medical practitioner who made the recommendation, arrange for the removal of the person to the approved centre by members of staff of the approved centre' (Section 13(2)). This applies to admissions under Section 9, which do not involve the Gardaí (Irish police). Under certain other circumstances, Gardaí may become involved, often necessitating further involvement on the part of the GP (depending on local arrangements); this is known as a Section 12 admission. As part of a Section 12 admission, the Gardaí transport the patient from their home to the Garda station, and then onwards to the approved centre, following an examination.

GPs' concern about transfer arrangements highlighted in this study presents particular cause for concern because difficulties with transport may, arguably, create an incentive to invoke Section 12 rather than Section 9; i.e. it may create an incentive towards the Section 12 procedure (which involves Gardaí transporting the patient) rather than the Section 9 procedure (which relies on the alternative transport arrangements that caused the GPs such concern in this study). This would be regrettable, as it would increase Gardaí involvement in what is already a difficult and stigmatising process for many patients.

Such a shift would also repeat the mistakes of the past. In the early 1800s, during a time of considerable legislative activity in relation to mental health, the Criminal Lunatics (Ireland) Act 1838 permitted the transfer of an individual to an asylum if they were considered dangerous and either mentally ill or intellectually disabled. This soon became the admission pathway of choice, partly because it gave the police full responsibility for transporting the individual to the asylum, which was then under an obligation to admit them ( $\mathrm{O}^{\prime}$ Neill, 2005). Consequently, the stigmatising and unnecessarily punitive 'dangerous lunacy' procedure was widely abused throughout the nineteenth century (Prior, 2003; Kelly, 2008). It would be deeply regrettable if concerns about transporting patients to approved centres under Section 9 of the Mental Health Act 2001 were to generate a similar reliance on police transport (under Section 12) in an era when de-stigmatising mental illness should be a priority for all (Kelly, 2005).

Ongoing improvements in transport arrangements to many approved centres have hopefully helped address this concern for GPs as experience with the legislation has grown in the years since its full implementation. It is hoped to repeat this study of GPs in the near future so as to determine which of the concerns highlighted in the present study remain valid for GPs as experience of the legislation has grown and mental health services have evolved over recent years.

\section{International perspectives}

Many of the issues highlighted in this study are not unique to Ireland. The increased administrative workload that GPs associated with the Mental Health Act 2001, for example, is also seen in other countries. South Africa, for example, introduced its new Mental Health Care Act No. 17 in 2004, seeking to dismantle apartheid practices that discriminated against the mentally ill and strengthen psychiatric services and protections of rights (e.g. through Mental Health Review Boards) (Ramlall, 2012). One of the chief problems reported with the new legislation, however, was 'the mountain of paper work involved' - a concern that is very similar to that of Irish GPs who report increased administrative workloads with the Mental Health Act 2001. In South Africa, as in Ireland, however, this increased workload needs to be set against the benefits of modernised legislation and the consequent protections of human rights.

Other countries experience other combinations of challenges as they reform their mental health laws, some of which overlap with concerns expressed in Ireland (Sheehan, 2009). In China, for example, mental health legislation is undergoing substantial change at present as a new mental health law was passed by the National People's Congress in October 2012, to come into effect in May 2013 (Qian, 2012). The chief anticipated problem in China, however, is the lack of qualified personnel and physical infrastructure to implement modernisation of the mental health system in general and, as a result, implement the new law in a consistent and meaningful fashion.

Revising mental health law may, however, also have unintended consequences and generate new issues among GPs and others which were not initially predicted. In England, for example, the introduction of the Mental Health Act 2007, which revised the Mental Health Act 1983, resulted in increased use of Section 2 (detention for assessment and/or treatment for up to 28 days) and decreased use of Section 3 (detention for treatment for up to 6 months) (Walker-Tilley et al. 2011). In addition, while the number of appeals against civil sections decreased, the proportion of appeals to mental health tribunals increased. The precise dynamics underlying these changes is not yet clear, and nor is the precise effect of the Mental Health Act 2007 on English general practice. Further research is needed in England and elsewhere, to determine the precise concerns of GPs in relation to reform of mental health legislation and its impact on primary care. 


\section{Conclusions}

Ireland's Mental Health Act 2001 greatly increased Ireland's compliance with human rights standards. Many of these improvements, however, depend on there being a broad-based understanding of, engagement with and enthusiasm for the legislation among all stakeholders, including GPs. The concerns and problems highlighted by GPs in this study may, arguably, hamper the likelihood of the legislation achieving its full potential to protect rights and enhance the experiences of individuals with mental illness.

This study, however, also generated several positive results. Many GPs highlighted a desire for structured training and enhanced guidelines. In addition, the forthright nature of many responses indicates that this is a topic with which GPs are deeply engaged and upon which they are eager to see real progress. This enthusiastic, progressive attitude highlights the potential that the Mental Health Act 2001 offers for real improvements in the involuntary admission process and the eagerness of GPs to see this potential realised, in the best interests of patients.

\section{Acknowledgements}

We are very grateful to the GPs who participated in this study.

\section{Conflicts of Interest}

None

\section{References}

Casey PR (2005). A Guide to Psychiatry in Primary Care, 3rd edn. Wrightson Biomedical Publishing: Petersfield, Hampshire.

Guéret M (2008). Irish Medical Directory: The Directory of Irish Healthcare 2007-2008. Irish Medical Directory: Dublin.

Jabbar F, Doherty AM, Aziz M, Kelly BD (2011).

Implementing the Mental Health Act 2007 in British general practice: lessons from Ireland. International Journal of Law and Psychiatry 34, 414-418.

Jabbar F, Kelly BD, Casey P (2010). National survey of psychiatrists' responses to implementation of the Mental Health Act 2001 in Ireland. Irish Journal of Medical Science 179, 291-294.
Kelly BD (2005). Stigma and mental illness. Irish Medical Journal 98, 37.

Kelly BD (2007). The Irish Mental Health Act 2001. Psychiatric Bulletin 31, 21-24.

Kelly BD (2008). Mental health law in Ireland, 1821-1902: building the asylums. Medico-Legal Journal 76, 19-25.

Kelly BD (2009a). The Mental Health Act 2007 in England and Wales: what does it mean? Irish Psychiatrist 10, 92-94.

Kelly BD (2009b). Community treatment orders under the Mental Health Act 2007 in England and Wales: lessons for Irish legislation? Medico-Legal Journal of Ireland 15, 43-48.

Kelly BD (2010). Mental health legislation and human rights in England, Wales and the Republic of Ireland. International Journal of Law and Psychiatry 34, 439-454.

Kelly M, O'Sullivan K, Finegan P, Moran J, Bradley C (2011). Assisted admissions? A national survey of general practitioner experience of involuntary admissions. Irish Medical Journal 104, 273-275.

NíMhaoláin Á, Kelly BD (2009). Ireland's Mental Health Act 2001: where are we now? Psychiatric Bulletin 33, 161-164.

O'Donoghue B, Moran P (2009). Consultant psychiatrists' experiences and attitudes following the introduction of the Mental Health Act 2001. Irish Journal of Psychological Medicine 26, 23-26.

O'Neill A-M (2005). Irish Mental Health Law. First Law: Dublin.

Prior P (2003). Dangerous lunacy: the misuse of mental health law in nineteenth-century Ireland. Journal of Forensic Psychiatry and Psychology 14, 525-541.

Qian J (2012). Mental health care in China: providing services for under-treated patients. Journal of Mental Health Policy and Economics 15, 179-186.

Ramlall S (2012). The Mental Health Care Act No. 17 - South Africa. Trials and triumphs: 2002-2012. African Journal of Psychiatry 15, 407-412.

Ramsay H, Roche E, O'Donoghue B (2013). Five years after implementation: a review of the Irish Mental Health Act 2001. International Journal of Law and Psychiatry 36, 83-91.

Sheehan KA (2009). Compulsory treatment in psychiatry. Current Opinion in Psychiatry 22, 582-586.

SPSS Inc. (2003). SPSS 12.0 Base Users Guide. Prentice-Hall Regents: Upper Saddle River, NJ.

United Nations (1991). Principles for the Protection of Persons with Mental Illness and the Improvement of Mental Health Care. United Nations: New York, NY.

Walker-Tilley T, Exworthy T, Baggaley M, Wilkinson L, Nilforooshan R (2011). Effect of recent changes to the Mental Health Act 1983 on sections and appeals: possible unintended consequences. The Psychiatrist 35, 305-307. 